\title{
Components of cultural complexity relating to emotions: A conceptual framework
}

\author{
Radek Trnka ${ }^{1,2}$, Iva Poláčková Šolcová ${ }^{3}$, Peter Tavel ${ }^{2}$
}

\author{
${ }^{1}$ Prague College of Psychosocial Studies, Milanska 471, 10900 Prague 10, Czech Republic \\ ${ }^{2}$ OUSHI, Palacky University, Univerzitni 22, 77111 Olomouc, Czech Republic \\ ${ }^{3}$ Institute of Psychology, Czech Academy of Science, Hybernska 8, 11000 Prague 1, Czech Republic
}

Note: This is the preprint version of the manuscript, the published article is available at https://doi.org/10.1016/j.newideapsych.2018.05.001

\begin{abstract}
Many cultural variations in emotions have been documented in previous research, but a general theoretical framework involving cultural sources of these variations is still missing. The main goal of the present study was to determine what components of cultural complexity interact with the emotional experience and behavior of individuals. The proposed framework conceptually distinguishes five main components of cultural complexity relating to emotions: 1) emotion language, 2) conceptual knowledge about emotions, 3) emotion-related values, 4) feelings rules, i.e. norms for subjective experience, and 5) display rules, i.e. norms for emotional expression.
\end{abstract}

\section{Introduction}

The issue of cultural variation has recently been of growing interest in various fields of psychological research (e.g., Clegg, Wen, \& Legare, 2017; Donaldson, Handren, Lindsay, \& Lac, 2017). Research in educational psychology (Ferrero, Garaizar, \& Vadillo, 2016; Wong, King, \& Pomeranz, 2016), personality psychology (Klasios, 2016; Park, Uchida, \& Kitayama, 2016; Trnka \& Cabelkova, 2016; Vignoles et al., 2016) and developmental psychology (Cheung \& Elliott, 2016; Jackson, Raval, Bendikas-King, Raval, \& Trivedi, 2016) has shown how various cultures shape self-construals, selfhood, beliefs or the parent-child boundary. Previous research also revealed some cultural variations in the ways people experience and express emotions.

Investigating cultural variations within the field of emotions is exceptionally important, because these variations may have serious applied impacts, e.g. on negotiation processes within strategic decision-making settings (Kopelman \& Rosette, 2008). Moreover, cross-cultural differences in emotion-related values may facilitate the emergence of prejudice and discrimination (Tsai \& Clobert, in press) and may also cause inequalities in employers' preferences for candidates to top leadership positions (Tsai \& Clobert, in press). Therefore, we consider further development of theory in this field to be very desirable.

Recent empirical evidence has shown that cultures vary in emotion-related values (e.g., Su, Wei, \& Tsai, 2014; Tsai \& Clobert, in press; Wei, Su, Carrera, Lin, \& Yi, 2013) as well as in complexity and differentiation of display rules, i.e. norms for emotional expression (Matsumoto, Yoo, \& Fontaine, 2009). This evidence indicates that cultures vary in the complexity of their structural backgrounds relating to emotions. Contemporary emotion theory covers plenty of specific areas, but a general theoretical framework involving cultural sources of variations in emotional experience and behavior is missing.

Cultures are highly complex dynamic systems (Chao \& Moon, 2005; Sherblom, 2017), and from this perspective we may posit a key question about what areas of cultural complexity are related to experience, expression and regulation of emotions (Pascuzzi \& Smorti, 2017) in individuals? At the beginning, it is necessary to say that individuals are not understood as being sharply separated from their cultural contexts within the dynamic systems perspective (Christopher \& Bickhard, 2007). The relationship between culture and a person is always interactive and actively and mutually constructed. Therefore, if we speak about experience, expression and regulation of emotions in individuals throughout this study, we will always consider the individual to be a part of a mutually interactive process.

The main goal of the present study is to determine what components, or subsystems, of cultural complexity interact in emotion constructions, i.e. participate in the emotional experience and behavior of individuals. We 
integrate theories from different areas of emotion research and provide an integrative conceptual framework for understanding cultural sources of variations related to emotions. The present study builds on complexity and dynamic systems thinking (e.g., Bickhard, 2000; Bickhard \& Campbell, 2003; Luhmann, 1995; RaczaszekLeonardi, 2016; Sherblom, 2017) while also utilizing evidence from cross-cultural research on emotions. In the following text, we will start with an operational definition of culture and emotion within the dynamic systems perspective. Further, we will continue in determining and operationalization of the five major components of cultural complexity relating to emotions: 1) emotion language, 2) conceptual knowledge about emotions, 3) emotion-related values, 4) feelings rules, i.e. norms for subjective experience, and 5) display rules, i.e. norms for emotional expression. Finally, we will discuss the implications and future questions for both theory and research.

\section{Emotion, culture and complexity}

The present study follows the dynamic systems model of emotions (Bickhard, 2000) and the theoretical framework of Matsumoto and Hwang (2012) providing operational definitions of emotions and culture. Emotions are "transient, bio-psycho-social reactions to events that have consequences for our welfare and potentially require immediate action." (Matsumoto \& Hwang, 2012, p. 92). We can understand emotions as general modes of interactive responses to situations of interactive uncertainty (Bickhard, 2000). They have the character of an information processing system reflecting the open dynamics of any living system. From this perspective, emotions are forms of interaction with the system's own internal dynamical uncertainty informing how to proceed and how to anticipate the interactive flow (Bickhard, 2000).

Human culture is defined as "a unique meaning and information system shared by a group and transmitted across generations" (Matsumoto \& Hwang, 2012, p. 95). Emotions are not independent of culture, because they emerge in the perpetual flow of momentary emotion constructions, i.e. during dynamic interactions between individuals and the socio-cultural context (Boiger \& Mesquita, in press; Witherington, 2017). They are relational in the sense that they are adaptations to a basic informational property of the organism-environment relationship (Bickhard, 2000). Emotions are largely functional to the sociocultural environment in which they occur (Mesquita \& Boiger, 2014). In other words, cultural contexts trigger different ways of how people make sense of the world, and these ways consequently also participate in dynamic constructions of emotional experiences and behaviors in time and space (Boiger \& Mesquita, in press).

Matsumoto and Hwang (2012) developed a preliminary theoretical conceptualization of various cultural influences on the emotional life of individuals (Figure 1). The first domain is the domain of priming reactions as immediate responses that occur in reaction to an event stimulus. Priming reactions are suggested as not requiring language or much conscious deliberation and, therefore, the contribution of culture within this domain is low relative to domains of subjective experience and emotion meanings. Subjective experience represents the second domain, and it covers self-reported experience, various forms of internal interpretations and labeling. This domain is influenced by culture more than is priming reactions, because it requires language as a verbal property provided by culture. Finally, attitudes, values, beliefs and concepts of emotion together represent the domain called emotion meanings. These constructs require higher-level cognitive skills, e.g. abstract thinking and memory, guiding how individuals should think about emotions (Imbir, 2016). This domain is apparently highly interrelated to cultural influences.

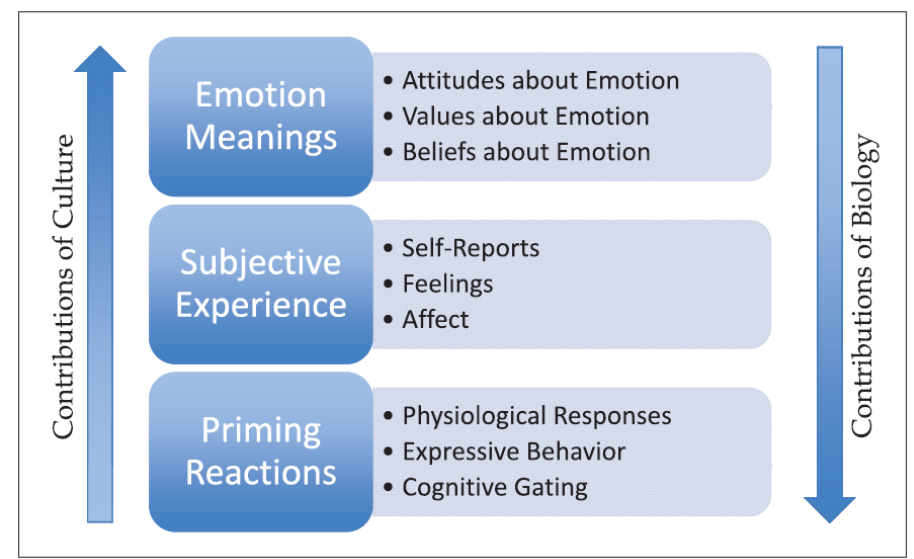

Figure 1. Three domains reflecting various degrees of cultural and biological influences on priming reactions, subjective experience and emotion meanings (Source: Matsumoto \& Hwang, 2012) 
The introduced framework covers both subject and cultural influences. In the present study we continue further in deeper operationalization of major cultural sources related to cultural variations within the realm of emotions. Generally, we understand culture as a broader system composed of parts, components or subsystems that are interdependently (or independently) related (Chao \& Moon, 2005). Previous cross-cultural research on emotions has revealed variations in various domains relating to emotional experience or behavior, for example, in cultural values and normative patterns of behavior. Various values, beliefs, representations, rules, scripts, prototypical actions and customs related to emotions may be identified in all cultures. We operationalize these fields as components or subsystems contributing to the overall complexity of a given culture.

The interaction of any system with its environment is bidirectional, i.e. the environment influences the system and the system influences the environment. Moreover, no sharp internal-external or objective-subjective divide can be made when analyzing dynamic, highly complex systems (Christopher \& Bickhard, 2007). For example, a culture should not be understood as being distinct from the person, because the individual should not be divided from his or her context (Christopher \& Bickhard, 2007). Thus, the relationship between culture and a person is always interactive, and therefore, a person's emotional experience or behavior are just part of a mutually interactive process.

Systems are dynamic, and they perpetually interact, evolve and adapt to changing environments (Bickhard, 2000; Bickhard \& Campbell, 2003; Chao \& Moon, 2005). In other words, systems are in a perpetual process of autopoietic differentiation (Bickhard, 2016; Luhmann, 1995; Triandis \& Suh, 2002), where autopoiesis means a self-producing mechanism that maintains the identity and existence of the system through self-reference, selfregulation and feedback. If we speak about cultural subsystems, such as cultural values, beliefs, representations or rules, we should accept that they are not stable and persistent over time. In contrast, cultural subsystems are emergent and always changing relational properties. Novelty is always possible, because new values, beliefs, representations or rules may emerge in a system's organization (Christopher \& Bickhard, 2007).

All cultures are differentiating all the time. Cultural values, beliefs, representations and rules are the results of emergence and autopoietic differentiation in time and space. However, these cultural elements are not autonomous subsystems but instead are deeply integrated in the basic interactive dynamic character of systems (Bickhard, 2000). What can be revealed by empirical research is the degree of differentiation within each subsystem, i.e. the differentiation in various values, representations, rules, scripts, prototypical actions or customs. The moment of measurement of some variable makes a cut in the sense of properties that can be observed in a given time and space. Therefore, when we measure any domain of cultural complexity, we always deal with temporal states of measured variables, because autopoietic differentiation proceeds perpetually in all systems. However, various degrees of differentiation of cultural subsystems may be determined in the moment of measurement, and the various degrees of differentiation denote what researchers call cultural variations in the areas reviewed at the beginning of this paper.

\section{Components of cultural complexity relating to emotions}

The following criteria were taken into account when determining the major components of cultural complexity relating to emotions: a) the area is a part of the cultural system, b) the area may participate in ways in which individuals experience, express or regulate their emotions, c) the area may be a potential source of cultural variations in emotions. We did not pay attention to cross-cultural differences in the cognitive processing of emotions, e.g. to emotional appraisals, antecedent events, event coding or action readiness (but see Mesquita \& Frijda, 1992). Further, we also did not consider sociopolitical factors, religious values and cultural influences on personality (but see Triandis \& Suh, 2002; van Hemert, Poortinga, van de Vijver, \& Fons, 2007).

Five main areas of cultural complexity relating to emotions were determined: 1) emotion language, 2) conceptual knowledge about emotions, 3) emotion-related values, 4) feelings rules, i.e. norms for subjective experience, and 5) display rules, i.e. norms for emotional expression (Figure 2). We consider these areas to be the main components, or subsystems, contributing in different ways to the structural background relating to emotions in a given culture.

Individuals in different cultures learn what kinds of emotional reactions are appropriate and also the range of acceptable behaviors within the given culture. Emotion norms, rules or scripts are back-end cultural regulation of emotional reactions. By regulating emotions via norms, cultures ensure that behaviors follow culturally prescribed scripts, increasing social coordination and decreasing social chaos (Matsumoto \& Hwang, 2012).

Language plays a key role in cultural constructions of concepts, attitudes, values and beliefs about emotion. Although biological emotions provide a platform for universal representations of emotional states in language, different cultures construct specific categories of emotion terms represented in a language as well as specific attitudes, values and beliefs (Matsumoto \& Hwang, 2012). In the following text, we will briefly introduce all the proposed components of cultural complexity relating to emotions. 


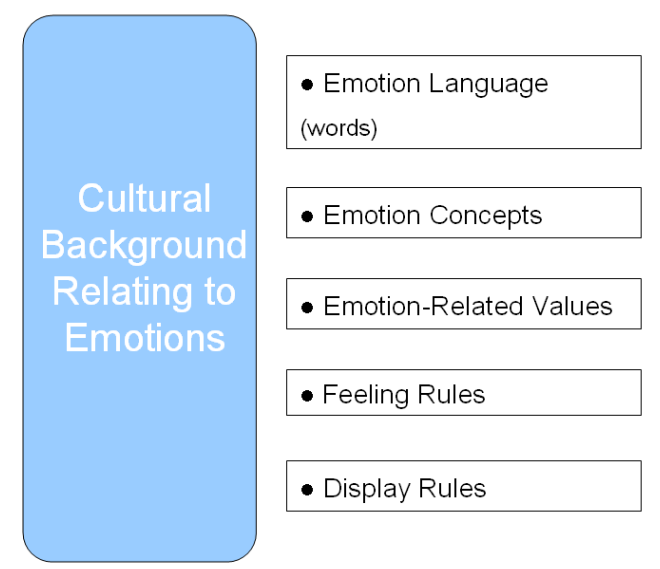

Figure 2. Components of cultural complexity relating to emotions.

\subsection{Emotion language}

Language is a basic tool that makes verbal communication of emotions possible. All languages include words that relate to emotional experiences and moods. Such linguistic labels for emotion categories in language are called emotion terms, emotion words or emotion names (Hupka, Lenton, \& Hutchinson, 1999; Trnka, Lacev, Balcar, Kuška, \& Tavel, 2016). Emotion terms help people to understand their own emotions, and they are conventionally understood as abstract representations with which people compare their real, everyday emotional experiences (but see, e.g., Bickhard, 2007; or Cowley, Stephen, \& Harvey, 2016 for different operational defining of language). Thus, different cultures have different emotion lexicons that include various amounts of emotion words that may be also less or more differentiated.

Comparing emotions across different languages has been done, e.g., within the Natural Semantic Metalanguage research program (e.g., Wierzbicka, 1999). It is beyond the scope of the present paper to review all the results of these cross-cultural comparisons here, but the main focus of this investigation was to reveal basic semantic primitives and how emotions are encoded, described and expressed in languages across cultures. Languages differ in the complexity of emotion lexicons, e.g. in the number of linguistic labels for different emotion categories. Most languages include the basic emotions (Ekman, 1999; Izard, 2007), but there are cultural variations in the number and semantic specificity of words for complex emotions, the number of synonymic words in emotion lexicons or the frequency of use of emotion words in everyday life.

The GRID methodology (Fontaine, Scherer, \& Soriano, 2013) is another way of comparing emotion words across cultures and languages. This methodology is focused on cognitive mechanisms responsible for emotion encoding and decoding through words. The meaning profiles of emotion words are analyzed through discrimination based on emotion component factors, such as valence appraisal, self versus other causation, or novelty appraisal. Semantic overlap of equivalent words across different languages and cultures may be determined based on this methodology (Scherer, 2013).

Investigation of emotion languages has shown some universals in the structures of emotion lexicons across cultures on one hand and various differentiations in the complexity of emotion lexicons on the other. Research on emotion lexicons and emotion words is very closely related to another domain: conceptual knowledge about emotions.

\subsection{Conceptual knowledge about emotions}

On the individual level of analysis, emotion concepts are abstract representations of the experiences of various emotions in one's own mind (Oosterwijk, Rotteveel, Fischer, \& Hess, 2009). They are components of the general emotion knowledge of a person (Oosterwijk et al., 2009) that is formed by storing previously experienced sensory, motor, physiological and introspective states. Emotion concepts are used for understanding emotional episodes during life events, and they help us make sense of our own emotions and the emotions of others.

Lindquist and Barrett (2008) as well as Mesquita and Boiger (2014) pointed out that cultures also vary in regard to conceptual knowledge about emotions. Emotion words and emotion concepts are closely related, but they do not mean the same thing. Emotion concepts are cultural prototypical scripts or scenarios, formulated in terms of thoughts, wants and feelings (Wierzbicka, 1992). Thus, conceptual knowledge about emotions covers culturally specific knowledge about what kinds of emotions there are, what the prototype of a particular emotion is, what situation typically elicits this emotion and what kind of behavior typically follows the emotion (Faucher \& Tappolet, 2008). 
There are some examples of cross-cultural research based on contrasting emotion concepts in different cultural groups. Church, Katigbak, Reyes and Jensen (1998) explored Filipino emotion concepts and compared them to English concepts. This study supported the universality of conceptual knowledge for most basic emotions, but the sample was limited and there is also the question of whether cultural variations in emotion concepts would be found when investigating complex emotions. Alvarado and Jameson (2011) compared emotion-term similarity judgments for monolingual and bilingual Vietnamese and English speakers in the United States and Vietnam. Despite the fact that emotion words for basic emotions showed similarity in the structure of conceptual emotion space, the authors concluded that greater cross-cultural differences in meaning were found just for complex emotions, e.g. for envy or shame.

\subsection{Emotion-related values}

Emotion-related values are cultural values related to preferences for some emotional experience or emotional regulation (Eid \& Diener, 2001; Tsai \& Clobert, in press). We can distinguish values focused on desirability of positive and negative emotions and values focused on emotional regulation.

Several empirical studies have investigated cultural variations in the experience of positive or negative emotions (Bagozzi, Wong, \& Yi, 1999; Grossmann, Huynh, \& Ellsworth, 2016; Kööts-Ausmees, Realo, \& Allik, 2012; Schimmack, Oishi, \& Diener, 2002; Yik, 2007). The co-occurrence of pleasant and unpleasant emotions has been found more prevalent in East Asian than in Western cultures (Bagozzi, Wong, \& Yi, 1999; Schimmack, Oishi, \& Diener, 2002). Tsai \& Clobert (in press) suggested that East Asian cultures value a balance between positive and negative emotions generally more than members of Western cultures. East Asian cultures also value less intense positive emotions more and highly intense positive emotions less than Western cultures. These findings mirror cultural variations in the desire to maximize positive and minimize negative emotional experience. There are three possible interpretations for this cultural variation.

First, Western cultures are believed to promote "independent" models of the self, where individuals are viewed as being distinct from others and prioritizing their own needs over those of others and understanding emotions as one's own private qualities that reflect the inner self (Grossmann, Huynh, \& Ellsworth, 2016; Markus \& Kitayama, 1991; Tsai \& Clobert, in press). In contrast, East Asian cultures promote "interdependent" models of the self, where individuals are viewed as being connected to others and seeing one's emotions as originating through interactions with other people (Grossmann, Huynh, \& Ellsworth, 2016; Markus \& Kitayama, 1991; Tsai \& Clobert, in press). These different models of the self may shape emotional experience in members of East Asian and Western cultures (Boiger, Mesquita, Uchida, \& Barrett, 2013).

Second, cultural variations in preferences for experience of positive or negative emotions may be interpreted by the prevalence of dialectical belief systems in a given culture. Generally, dialectical beliefs are related to the complementarity of opposites and the view that life is full of contradictions (Grossmann, Huynh, \& Ellsworth, 2016; Nisbett, Peng, Choi, \& Norenzayan, 2001). Within the psychology of emotion, emotional dialecticism denotes the complexity of subjective emotional experience and refers to the experience of pleasant and unpleasant emotional states in a coincidental or temporally related fashion (Bagozzi, Wong, \& Yi, 1999; Lindquist \& Barrett, 2008). The concept of emotional dialecticism is one of two operational definitions of emotional complexity. The second definition, emotional differentiation, refers to the ability to experience emotions in a highly differentiated manner with a greater variety of negative and positive discrete emotions (Grossmann \& Ellsworth, 2017; Grossmann, Huynh, \& Ellsworth, 2016; Grühn, Lumley, Diehl, \& Labouvie-Vief, 2013). A similar concept of emotional granularity (Kashdan, Barrett, \& McKnight, 2015; Lindquist \& Barrett, 2008) denotes the verbal ability of individuals to express emotional experiences with precision and specificity.

Third, cultural variations in the experience of positive or negative emotions may also be related to the prevalence of Hofstede's (2001) uncertainty avoidance dimension in a given culture. Cultures high on uncertainty avoidance showed more frequent experience of negative emotions and less frequent experience of positive emotions than low uncertainty avoidance cultures (Hofstede, 2001).

Let us turn our attention to emotion-related values that are related to cultural endorsement of strategies of emotional regulation or, more specifically, to preference for either emotional expression or emotional suppression in a given culture. East Asian cultures generally value emotional expression less and suppression more than Western cultures (Butler, Lee, \& Gross, 2007; Ford \& Mauss, 2015; Su, Wei, \& Tsai, 2014; Tsai \& Clobert, in press; Wei et al., 2013). The study of Eid and Diener (2001) was focused on desired and undesired emotions in the United States, Australia, Taiwan and China. The participants from China consistently showed the lowest experiences in almost all kinds of emotions. The authors interpreted this finding by the general value that emotions have in China, where there is a general attitude to consider emotions as dangerous, irrelevant or even illnesscausing (Eid \& Diener, 2001). Regulation strategies, such as the suppression of emotions, are generally suggested to be highly valued in East Asian cultures, and the value of a moderated emotional life can also be found in these cultures. Cultural endorsement of strategies of emotional regulation may also be possibly related to Hofstede's (2001) individualism-collectivism dimension, because highly individualistic cultures also showed higher levels of general emotional expression (van Hemert et al., 2007). 
Aside from the above-mentioned link between the general preference to experience positive or negative emotions and dialectical belief systems, some links between the core values of Schwartz (Schwartz, 1992; Schwartz et al., 2012) and the experience of discrete emotions were revealed by previous research. Tamir et al. (2015) brought evidence that the values of self-transcendence, self-enhancement, openness to change and conservation have been proved to be related to desired experience of particular discrete emotions (Table 1 and 6 in Tamir et al. 2015). This coherence has been found for samples from 8 distinct cultures: the United States, Brazil, China, Germany, Ghana, Israel, Poland and Singapore. Although cultures varied in both values and preferences for desired emotions (Figure 2, Tamir et al. 2015), the core values of Schwartz were shown to be closely related to emotion-related values. The results of this study indicated that in cultures highlighting self-transcendence, love and empathy are more desired. Values related to self-enhancement were found to be linked with more valued pride, anger and contempt. Openness to change was linked with more desired interest and excitement, and values related to conservation were found to be related with more calmness and less desired fear. These patterns mostly persisted across different cultural samples. There is also evidence indicating that some discrete emotions, e.g. anger and shame, may be related to defending honor in some cultures (Boiger, Güngör, Karasawa, \& Mesquita, 2014).

\subsection{Feeling rules}

Different cultures have different feeling rules (Hochschild, 1983), i.e. rules that prescribe what emotions people should feel in specific situations. Feeling rules are generalized expectations about the appropriateness of emotional experiences in different contexts, and they may influence the readiness or propensity to experience various discrete emotions (Bickhard, 2000). Thus, discrete emotions vary in their desirability and perceived appropriateness across different cultures (Eid \& Diener, 2001). Feeling rules are similar to emotion-related values, but they are more specific, i.e. focused more on the appropriateness of the experience of discrete emotions in specific contexts. However, it is likely that feeling rules may be derived from higher-order emotion-related values, which may be understood as a superordinate structure for feeling rules.

Cross-cultural research on feeling rules is relatively sparse. Eid and Diener (2001) investigated feeling rules for joy, affection, pride, contentment, anger, fear, sadness and guilt in two individualistic (United States, Australia) and two collectivistic (China, Taiwan) cultures. The participants were asked how appropriate or desirable it is to experience certain emotions. The results revealed interesting differences in feeling rules for pride and guilt between countries. In more collectivistic cultures guilt was more appropriate, whereas in individualistic cultures pride is of greater relevance (Eid \& Diener, 2001). The authors interpreted these findings with the assumption that approachoriented, individualistic cultures prefer self-reflective emotions about an individual's own successful actions, whereas collectivistic, Confucian cultures prefer self-reflective emotions indicating an individual's failures or situations in which one's controllable actions are wrong. These results indicated that feeling rules for self-reflective emotions is a rich source of cultural variations in emotional experience.

\subsection{Display rules}

Display rules are cultural norms focused on the management and modification of emotional expressions depending on social circumstances (Ekman \& Friesen, 1969). They facilitate the course of interactions between social agents, and from this view they also regulate social interactions (Bickhard, 2000). Two general areas of research of display rules may be distinguished: research of display rules in the nonverbal domain and research of display rules for verbal emotional expressions. Let us to start with display rules in the nonverbal domain.

The most comprehensive assessment of display rules around the world was conducted by Matsumoto, Yoo, \& Fontaine (2009). This comprehensive survey included 32 countries and used the Display Rule Assessment Inventory (Matsumoto, Yoo, \& Fontaine, 2009), which measures display rules for 7 emotions (anger, contempt, disgust, fear, happiness, sadness and surprise) in two settings (public and private) and across many interacting targets, e.g., father, mother, brother, sister, close friend, acquaintance, when alone, etc. The results of this crosscultural study revealed important cultural differences in overall expressivity norms and variations in complexity of display rules (Matsumoto, Yoo, \& Fontaine, 2009). Some cultures encourage large differentiations among their members' behaviors across contexts, while others discourage such differentiation. High context differentiating cultures (HCD cultures) are suggested to encourage differentiation of behavior in different contexts, and thus display rules are less complex and differentiated. In contrast, low context differentiating cultures (LCD cultures) enable their members to differentiate their behaviors relatively less across contexts. In these cultures a more complex system of display rules can be found, and consistency of emotional behavior across contexts would be the norm. People who come from LCD cultures and/or who do not differentiate their behaviors much across contexts may be seen as immature in HCD cultures.

Let's shift the attention to display rules for verbal emotional expressions. This area of research is relatively sparse (see, e.g., the older study of Cosnier, Dols, \& Fernandez, 1986). Fernández, Carrera, Sánchez, Paez \& Candia (2000) conducted a large cross-cultural study including samples from 21 cultures. They explored various kinds of display rules for joy, sadness and anger in both the verbal and nonverbal domains. European and North American cultures reported higher emotional verbal and non-verbal expression than Asian and Latin American 
cultures in sadness and anger. Asian cultures had homogeneously the lowest level of emotional expression in all emotions, including joy. In contrast, Latin Americans reported higher levels of emotional expression in joy in comparison to Asians and similar to that of the Euro-American participants (see Tables 4 and 5 in Fernández et al., 2000, for more details). Collectivist, higher power distance and masculine countries had more complex and differentiated rules for emotional expression especially in the case of negative emotions.

\section{Discussion}

The present study offers several implications for future research and theory development. First, the aboveoutlined components of cultural complexity relating to emotions have different functions and also vary in functional range. The functions of some components are more specifically targeted, while others are more universal. For example, display rules and feelings rules are norms of what to feel and express in certain contexts. These norms are suggested to be active only during emotional episodes or emotional communication. In contrast, emotion language, conceptual knowledge about emotions and emotion-related values are more universal cultural components that have a high variability in influencing the members of a given culture. Emotion words are a part of the linguistic lexicon of a culture, and therefore, emotion words are also used in contexts when a subject may not experience any emotion, i.e. in narratives, media broadcasts or written content. Further, the functional range of emotion-related values is very difficult to determine, because emotion-related values may implicitly influence many other domains of human behavior than only emotional events or emotional communication. Further elaboration is needed in this field, but we may preliminarily state that components of cultural complexity relating to emotions vary in their functional range, i.e. from a narrower functional range to a broader functional range.

Second, the boundaries of the above-outlined subsystems of cultural complexity are not sharp. In contrast, some overlap can be found between subsystems of cultural complexity. However, this is not surprising when analyzing highly complex systems such as cultures. In that case, boundaries are often fluid rather than sharp, and some overlap may occur between various subsystems. For example, display rules and feelings rules may be understood as kinds of emotion-related values. Despite the fact that emotion-related values are more general constructs in terms of, e.g., preferences for some broader group of emotions in a given culture, it seems that all these subsystems are inter-connected. For future discussions, we also posit the alternative possibility to understand feelings rules, display rules and emotion-related values as a broader interconnected complex of feelings rules $\times$ display rules $\times$ emotion-related values.

Third, some components of cultural complexity relating to emotions represent a background for subjective emotional complexity. For example, emotional granularity (Lindquist \& Barrett, 2008), i.e. the verbal ability of individuals to express emotional experiences with precision and specificity, relates to the emotion language and emotion concepts of a given culture, as different cultures have various numbers and semantic specificity of emotion words. The cultural emotion lexicon is the basic substrate from which the verbal repertoire of individuals can be developed. Therefore, emotional granularity relating to differentiated verbal repertoires of individuals may also be closely connected with the emotion language and emotion concepts of a given culture. These links show how the relationship between culture and the person is mutually constructed.

Fourth, cross-cultural research in display rules has shown that some cultures have less complex and differentiated display rules than others (Matsumoto, Yoo, \& Fontaine, 2009). This finding has an important implication for cultural psychological theory, especially within the context of compliance to cultural norms. Triandis \& Suh (2002) distinguish between tight cultures and loose cultures. In tight cultures, norms are imposed more strictly than in loose cultures (Triandis \& Suh, 2002). Within this perspective, we may ask if variations in compliance to cultural norms may be related to the degree of context differentiation in the cultural subsystem of display rules? We may hypothesize that tight cultures (Triandis \& Suh, 2002) would also have highly differentiated display rules, and loose cultures would have less differentiated display rules. Future research is needed to explore this hypothesis.

There are also several questions remaining for future development in this field. Recently, some scholars discussed the issue of historical homogeneity or heterogeneity, i.e. the extent to which a country's present-day population descended from relatively homogeneous origins or much more from migrations from numerous source countries (e.g., Rychlowska et al., 2015). We hypothesize that this cultural factor may influence the form of differentiation of cultural subsystems. It is likely that mixing influences from different cultural origins may also influence higher heterogeneity in emotion-related values, norms and rules. At the same time, the effect of emotional acculturation should be considered, i.e. the tendency of migrants to adjust their emotional patterns to those of their culture of settlement (De Leersnyder, Mesquita, \& Kim, 2011). Future cross-cultural research of emotion should take both of these influences into account.

Further, cultures are such highly complex systems that we face a quite difficult task when we try to determine the mutual relationships between their subsystems. Mutual interactions between different subsystems are always present in most highly complex systems. Therefore, it is also likely that display rules, feelings rules, emotion language, conceptual knowledge about emotions and emotion-related values are not independent, but deeply interrelated components. At this moment, it is difficult to define mutual interactions between components of 
cultural complexity relating to emotions. Future research and theorizing is needed to clarify this issue; however, we may provide at least a hypothetical schema of possible interactions between the components of cultural complexity relating to emotions (Figure 3). We are aware that this schema is speculative at this moment because of the lack of empirical evidence and that it merely aims to stimulate future follow-up discussions. Future research may clarify this issue and provide a more exact framework for mutual interactions between components of cultural complexity relating to emotions.
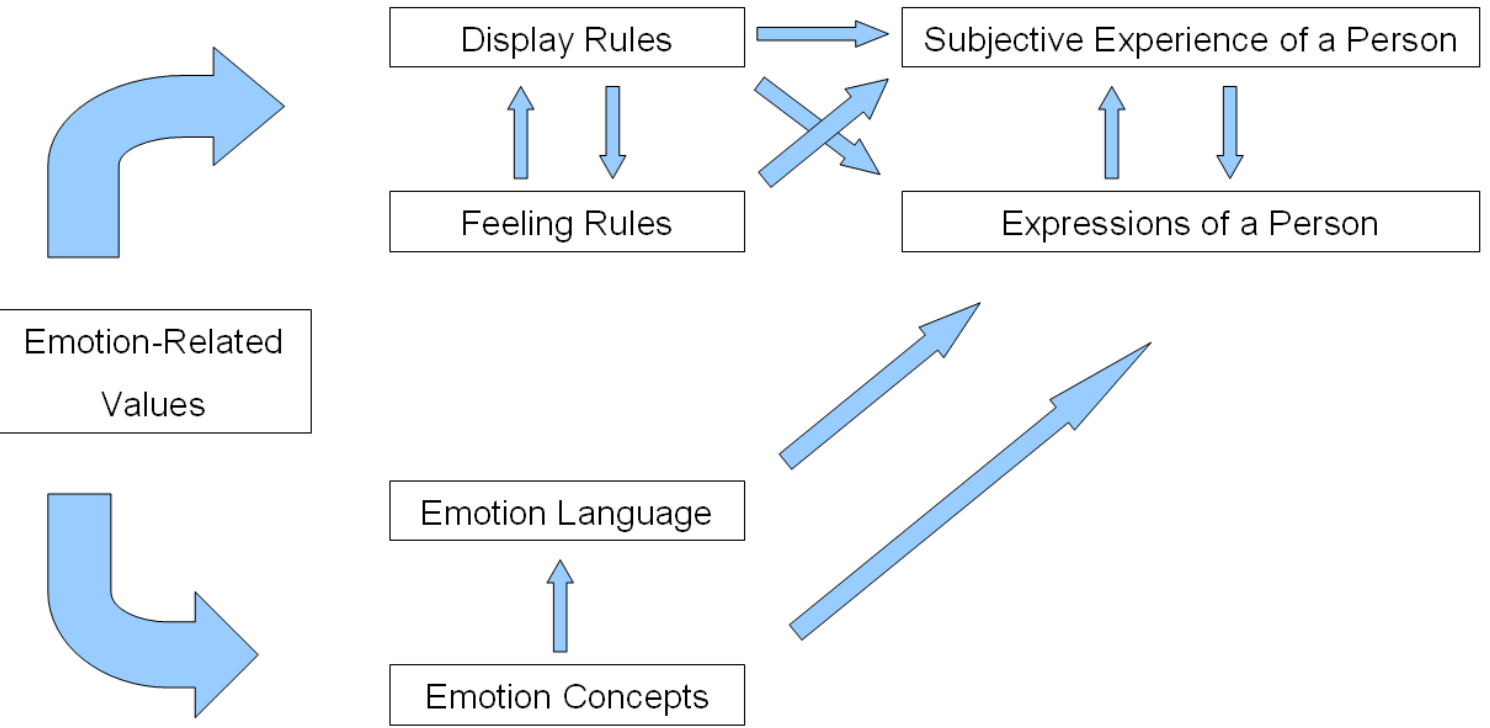

Figure 3. Model of relationships between components of cultural complexity relating to emotions and emotional experience and expressions.

\section{Conclusions}

The main aim of this study was to develop a general theoretical framework for investigating cultural sources of variations in emotional experience and behavior. We determined five main subsystems: 1) emotion language, 2) conceptual knowledge about emotions, 3) emotion-related values, 4) feelings rules and 5) display rules (Figure 2). We consider these areas to be components of cultural complexity relating to emotions. This preliminary theoretical conceptualization aims to provide a general theoretical framework for interpreting cultural variations in emotions that have been revealed by previous research. Further, the proposed conceptualization may inspire future theory-informed cross-cultural designs and provide an inspiring background for interpreting the results of cross-cultural research across different fields of psychology.

\section{Acknowledgements}

Many thanks to David Matsumoto and Hyi Sung Hwang, who kindly provided us with very valuable comments in the initial stage of manuscript preparation as well as with the final version of the manuscript. This paper was assisted by RVO: 68081740 as a part of research programme of Czech Academy of Sciences, Strategy AV21.

\section{References}

Alvarado, N., \& Jameson, K. A. (2011). Shared knowledge about emotion among Vietnamese and English bilingual and monolingual speakers. Journal of Cross-Cultural Psychology, 42(6), 963-982.

Bagozzi, R. P., Wong, N., \& Yi, Y. (1999). The role of culture and gender in the relationship between positive and negative affect. Cognition and Emotion, 13(6), 641-672.

Bickhard, M. H. (2000). Motivation and emotion: An interactive process model. In R. D. Ellis, \& N. Newton (Eds.), The caldron of consciousness: Motivation, affect and self-organization - An anthology (pp. 161-178). Amsterdam: J. Benjamins.

Bickhard, M. H. (2016). Inter- and En- activism: Some thoughts and comparisons. New Ideas in Psychology, 41, 23-32. 
Bickhard, M. H. (2007). Language as an interaction system. New Ideas in Psychology, 25(2), 171-187.

Bickhard, M. H., \& Campbell, D. T. (2003). Variations in variation and selection: The ubiquity of the variationand-selective retention ratchet in emergent organizational complexity. Foundations of Science, 8(3), 215282.

Boiger, M., \& Mesquita, B. (in press). A socio-dynamic perspective on the construction of emotion. In L. F. Barrett \& J. A. Russell (Eds.), The psychological construction of emotion (pp. 377-398). New York, NY: Guilford.

Boiger, M., Güngör, D., Karasawa, M., \& Mesquita, B. (2014). Defending honour, keeping face: Interpersonal affordances of anger and shame in Turkey and Japan. Cognition and Emotion, 28(7), 1255-1269.

Boiger, M., Mesquita, B., Uchida, Y., \& Barrett, L. F. (2013). Condoned or condemned: The situational affordance of anger and shame in the United States and Japan. Personality and Social Psychology Bulletin, 39(4), 540-553.

Butler, E. A., Lee, T. L., \& Gross, J. J. (2007). Emotion regulation and culture: Are the social consequences of emotion suppression culture-specific? Emotion, 7(1), 30-48.

Chao GT., Moon H (2005). The cultural mosaic: A metatheory for understanding the complexity of culture. Journal of Applied Psychology, 90(6), 1128-1140.

Cheung, H. S., \& Elliott, J. M. (2016). Measuring maternal sensitivity: Cultural variations in the measurement of emotional availability. Child Development, 87(3), 898-915.

Christopher, J. C., \& Bickhard, M. H. (2007). Culture, self and identity: Interactivist contributions to a metatheory for cultural psychology. Culture \& Psychology, 13(3), 259-295.

Clegg, J. M., Wen, N. J., \& Legare, C. H. (2017). Is non-conformity WEIRD? Cultural variation in adults' beliefs about children's competency and conformity. Journal of Experimental Psychology: General, 146(3), 428-441.

Church, T., Katigbak, M. S., Reyes, J. A. S., \& Jensen, S. M. (1998). Language and organisation of Filipino emotion concepts: Comparing emotion concepts and dimensions across cultures. Cognition \& Emotion, 12(1), 63-92.

Cosnier, J., Dols, J. M. F., \& Fernandez, A. J. (1986). The verbalization of emotional experiences. In K. R. Scherer, H. G. Wallbott, \& A. B. Summerfield (Eds.), Experiencing emotion: A cross-cultural study (pp. 117-128). Cambridge: Cambridge University Press.

Cowley, S. J., \& Harvey, M. I. (2016). The illusion of common ground. New Ideas in Psychology, 42, 56-63.

De Leersnyder, J., Mesquita, B., \& Kim, H. S. (2011). Where do my emotions belong? A study of immigrants' emotional acculturation. Personality and Social Psychology Bulletin, 37(4), 451-463.

Donaldson, C. D., Handren, L. M., \& Lac, A. (2017). Applying multilevel modeling to understand individual and cross-cultural variations in attitudes toward homosexual people across 28 European countries. Journal of Cross-Cultural Psychology, 48(1), 93-112.

Eid, M., \& Diener, E. (2001). Norms for experiencing emotions in different cultures: inter-and intranational differences. Journal of Personality and Social Psychology, 81(5), 869-885.

Ekman, P. (1999). Basic emotions. In T. Dalgleish \& T. Power (Eds.), The handbook of cognition and emotion (pp. 45-60). Sussex, UK: John Wiley and Sons.

Faucher, L., \& Tappolet, C. (2008). Facts and values in emotional plasticity. In L. C. Charland and P. Zachar (Eds.), Facts and value in emotion (pp. 101-137). Amsterdam: John Benjamins Publishing Company.

Ferrero, M., Garaizar, P., \& Vadillo, M. A. (2016). Neuromyths in education: Prevalence among Spanish teachers and an exploration of cross-cultural variation. Frontiers in Human Neuroscience, 10.

Fernández, I., Carrera, P., Sánchez, F., Paez, D., \& Candia, L. (2000). Differences between cultures in emotional verbal and non-verbal reactions. Psicothema, 12(Su1), 83-92.

Fontaine, J. J., Scherer, K. R., \& Soriano, C. (Eds.). (2013). Components of emotional meaning: A sourcebook. Oxford: Oxford University Press.

Ford, B. Q., \& Mauss, I. B. (2015). Culture and emotion regulation. Current Opinion in Psychology, 3, 1-5.

Grossmann, I., \& Ellsworth, P. C. (2017). What are mixed emotions and what conditions foster them? Life-span experiences, culture and social awareness. Current Opinion in Behavioral Sciences, 15, 1-5. 
Grossmann, I., Huynh, A. C., \& Ellsworth, P. C. (2016). Emotional complexity: Clarifying definitions and cultural correlates. Journal of Personality and Social Psychology, 111(6), 895-916.

Grühn, D., Lumley, M. A., Diehl, M., \& Labouvie-Vief, G. (2013). Time-based indicators of emotional complexity: Interrelations and correlates. Emotion, 13(2), 226-237.

Hochschild, R. (1983). The managed heart. Berkeley, CA: University of California Press.

Hofstede, G., Hofstede, G. J., \& Minkov, M. (2010). Cultures and organizations: Software of the mind. Intercultural cooperation and its importance for survival. New York: McGraw Hill.

Hupka, R. B., Lenton, A. P., \& Hutchison, K. A. (1999). Universal development of emotion categories in natural language. Journal of Personality and Social Psychology, 77(2), 247-278.

Imbir, K. K. (2016). From heart to mind and back again. A duality of emotion overview on emotion-cognition interactions. New Ideas in Psychology, 43, 39-49.

Izard, C. E. (2007). Basic emotions, natural kinds, emotion schemas, and a new paradigm. Perspectives on Psychological Science, 2(3), 260-280.

Jackson, E. F., Raval, V. V., Bendikas-King, E. A., Raval, P. H., \& Trivedi, S. S. (2016). Cultural variation in reports of subjective experience of parent-child boundary dissolution among emerging adults. Journal of Family Issues, 37(5), 671-691.

Kashdan, T. B., Barrett, L. F., \& McKnight, P. E. (2015). Unpacking emotion differentiation: Transforming unpleasant experience by perceiving distinctions in negativity. Current Directions in Psychological Science, 24(1), 10-16.

Klasios, J. (2016). Evolutionizing human nature. New Ideas in Psychology, 40, 103-114.

Kopelman, S., \& Rosette, A. S. (2008). Cultural variation in response to strategic emotions in negotiations. Group Decision and Negotiation, 17(1), 65-77.

Kööts-Ausmees, L., Realo, A., \& Allik, J. (2013). The relationship between life satisfaction and emotional experience in 21 European countries. Journal of Cross-Cultural Psychology, 44(2), 223-244.

Linquist, K. A., Barrett, L. F. (2008). Emotional complexity. In M. Lewis, J. M. Haviland-Jones, \& L.F. Barrett (Eds.), The handbook of emotions (pp. 513-530). New York: Guilford.

Luhmann, N. (1995). Social systems. Stanford: Stanford University Press.

Matsumoto, D., \& Hwang, H. S. (2012). Culture and emotion: The integration of biological and cultural contributions. Journal of Cross-Cultural Psychology, 43(1), 91-118.

Matsumoto, D., Yoo, S. H., \& Fontaine, J. (2009). Hypocrisy or Maturity? Culture and Context Differentiation. European Journal of Personality, 23(3), 251-264.

Mesquita, B., \& Boiger, M. (2014). Emotions in context: A sociodynamic model of emotions. Emotion Review, 6(4), 298-302.

Mesquita, B., \& Frijda, N. H. (1992). Cultural variations in emotions: a review. Psychological Bulletin, 112(2), 179-204.

Nisbett, R. E., Peng, K., Choi, I., \& Norenzayan, A. (2001). Culture and systems of thought: Holistic vs. analytic cognition. Psychological Review, 108(2), 291-310.

Oosterwijk, S., Rotteveel, M., Fischer, A. H., \& Hess, U. (2009). Embodied emotion concepts: How generating words about pride and disappointment influences posture. European Journal of Social Psychology, 39(3), 457-466.

Park, J., Uchida, Y., \& Kitayama, S. (2016). Cultural variation in implicit independence: An extension of Kitayama et al. International Journal of Psychology, 51(4), 269-278.

Pascuzzi, D., \& Smorti, A. (2017). Emotion regulation, autobiographical memories and life narratives. New Ideas in Psychology, 45, 28-37.

Rączaszek-Leonardi, J. (2016). How does a word become a message? An illustration on a developmental timescale. New Ideas in Psychology, 42, 46-55.

Rychlowska, M., Miyamoto, Y., Matsumoto, D., Hess, U., Gilboa-Schechtman, E., Kamble, S., Muluk, H., Masuda, T., \& Niedenthal, P. M. (2015). Heterogeneity of long-history migration explains cultural differences in reports of emotional expressivity and the functions of smiles. Proceedings of the National Academy of Sciences, 112(19), 2429-2436. 
Scherer, K. R. (2013). Measuring the meaning of emotion words: A domain-specific componential approach, in J. R. J. Fontaine, K. R. Scherer, \& C. Soriano (Eds.), Components of emotional meaning: A sourcebook (pp. 7-30). Oxford: Oxford University Press.

Schimmack, U., Oishi, S., \& Diener, E. (2002). Cultural influences on the relation between pleasant emotions and unpleasant emotions: Asian dialectic philosophies or individualism-collectivism? Cognition and Emotion, 16(6), 705-719.

Sherblom, S. A. (2017). Complexity-thinking and social science: Self-organization involving human consciousness. New Ideas in Psychology, 47, 10-15.

Su, J. C., Wei, M., \& Tsai, H. T. (2014). Running away from unwanted feelings: culture matters. Cognition and Emotion, 28(7), 1313-1327.

Schwartz, S. H. (1992). Universals in the content and structure of values: Theoretical advances and empirical tests in 20 countries. Advances in Experimental Social Psychology, 25, 1-65.

Schwartz, S. H., Cieciuch, J., Vecchione, M., Davidov, E., Fischer, R., Beierlein, C., ... \& Dirilen-Gumus, O. (2012). Refining the theory of basic individual values. Journal of Personality and Social Psychology, 103(4), 663-688.

Triandis, H. C., \& Suh, E. M. (2002). Cultural influences on personality. Annual Review of Psychology, 53(1), 133-160.

Trnka, R., Cabelkova, I. (2016). Neuroticism across cultures: Macro-level insights into the worldwide distribution of neuroticism. In A. Di Fabio (Ed.), Neuroticism: Characteristics, impact on job performance, and health outcomes (pp. 161-185). New York: Nova Science Publishers.

Trnka, R., Lacev, A., Balcar, K., Kuška, M., \& Tavel, P. (2016). Modeling semantic emotion space using a 3D hypercube-projection: an innovative analytical approach for the psychology of emotions. Frontiers in Psychology, 7, art.n. 522.

Tsai, J., \& Clobert, M. (in press). Cultural influences on emotion: Empirical patterns and emerging trends. In S. Kitayama, \& D. Cohen (Eds). Handbook of cultural psychology. Oxford: Oxford University Press.

Vignoles, V. L., Owe, E., Becker, M., Smith, P. B., Easterbrook, M. J., Brown, R., ... \& Lay, S. (2016). Beyond the 'east-west' dichotomy: Global variation in cultural models of selfhood. Journal of Experimental Psychology: General, 145(8), 966-1000.

Wei, M., Su, J. C., Carrera, S., Lin, S. P., \& Yi, F. (2013). Suppression and interpersonal harmony: A crosscultural comparison between Chinese and European Americans. Journal of Counseling Psychology, 60(4), 625 .

Wierzbicka, A. (1992). Defining emotion concepts. Cognitive Science, 16(4), 539-581.

Wierzbicka, A. (1999). Emotions across languages and cultures. Cambridge: Cambridge University Press.

Witherington, D. C. (2017). The explanatory significance of wholes: How exclusive reliance on antecedentconsequent models of explanation undermines the study of persons. New Ideas in Psychology, 44, 14-20.

Wong, T. J., King, J. L., \& Pomeranz, J. L. (2016). Cultural variation in antismoking video ads between the United States, Taiwan, and China. Health Education Research, 31(5), 603-613.

Van Hemert, D. A., Poortinga, Y. H., \& van de Vijver, F. J. (2007). Emotion and culture: A metaanalysis. Cognition and Emotion, 21(5), 913-943.

Yik, M. (2007). Culture, gender, and the bipolarity of momentary affect. Cognition and Emotion, 21(3), 664680 . 